\title{
The genome and proteome of a virulent Escherichia coli O I 57:H7 bacteriophage closely resembling Salmonella phage Felix O I
} Andre Villegas ${ }^{1}$, Yi-Min She ${ }^{2}$, Andrew M Kropinski1,3, Erika J Lingohr ${ }^{1}$, Amanda Mazzocco ${ }^{1}$, Shivani Ojha ${ }^{1}$, Thomas E Waddell ${ }^{4}$, HansWolfgang Ackermann ${ }^{5}$, Dianne M Moyles ${ }^{3}$, Rafiq Ahmed ${ }^{6}$ and Roger P Johnson*1

\begin{abstract}
Address: ${ }^{1}$ Public Health Agency of Canada, Laboratory for Foodborne Zoonoses, 110 Stone Road West, Guelph, ON, N1G 3W4, Canada, ${ }^{2}$ Centre for Biologics Research, Biologics and Genetic Therapies Directorate, Health Canada, 251 Sir Frederick Banting Driveway, Tunney's Pasture, Ottawa, ON, K1A 0K9, Canada, ${ }^{3}$ Department of Molecular \& Cellular Biology, University of Guelph, Guelph, ON, N1G 2W1, Canada, ${ }^{4}$ Pro-Lab Developments Inc, 200 Gerrard Street E, Suite 300, Toronto, ON, M5A 2E6, Canada, 5Département de Biologie médicale, Faculté de médecine, Université Laval, Québec, QC, G1K 7P4, Canada and 'Public Health Agency of Canada, National Microbiology Laboratory, Canadian Science Centre for Human and Animal Health, 1015 Arlington Street, Winnipeg, MB, R3E 3R2, Canada

Email: Andre Villegas - Andre_Villegas@phac-aspc.gc.ca; Yi-Min She - Yi-Min_She@hc-sc.gc.ca; Andrew M Kropinski - kropinsk@queensu.ca; Erika J Lingohr - Erika_Lingohr@phac-aspc.gc.ca; Amanda Mazzocco - Amanda_Mazzocco@phac-aspc.gc.ca; Shivani Ojha - sojha@uoguelph.ca; Thomas E Waddell - tom.waddell@pro-lab.com; Hans-Wolfgang Ackermann - ackermann4@gmail.com;

Dianne M Moyles - dmoyles@uoguelph.ca; Rafiq Ahmed - Rafiq_Ahmed@phac-aspc.gc.ca; Roger P Johnson* - Roger_Johnson@phac-aspc.gc.ca

* Corresponding author
\end{abstract}

Published: 20 April 2009

Virology Journal 2009, 6:4 I doi:10.1186/1743-422X-6-4I

This article is available from: http://www.virologyj.com/content/6/l/4I

(C) 2009 Villegas et al; licensee BioMed Central Ltd.

This is an Open Access article distributed under the terms of the Creative Commons Attribution License (http://creativecommons.org/licenses/by/2.0), which permits unrestricted use, distribution, and reproduction in any medium, provided the original work is properly cited.

\begin{abstract}
Based upon whole genome and proteome analysis, Escherichia coli OI57:H7-specific bacteriophage (phage) wV8 belongs to the new myoviral genus, "the Felix OI-like viruses" along with Salmonella phage Felix OI and Erwinia amylovora phage $\phi E a 2 I-4$. The genome characteristics of phage wV8 (size $88.49 \mathrm{~kb}, \mathrm{~mol} \% \mathrm{G}+\mathrm{C} 38.9$, I38 ORFs, 23 tRNAs) are very similar to those of phage Felix OI (86.16 kb, $39.0 \mathrm{~mol} \% \mathrm{G}+\mathrm{C}, \mathrm{I} 3 \mathrm{I}$ ORFs and $22 \mathrm{tRNAs}$ ) and, indeed most of the proteins have their closest homologs within Felix OI. Approximately one-half of the Escherichia coli OI57:H7 mutants resistant to phage wV8 still serotype as O157:H7 indicating that this phage may recognize, like coliphage T4, two different surface receptors: lipopolysaccharide and, perhaps, an outer membrane protein.
\end{abstract}

\section{Findings}

Bacteriophages (phages) are promising potential alternatives to antibiotics as therapeutics to reduce carriage of pathogens by food animals, thus preventing the spread of organisms such as Escherichia coli O157:H7 along the food chain. Our research has shown that a cocktail of virulent phages can eliminate E. coli O157:H7 from experimentally infected calves $[1,2]$. Phage V8, isolated originally from sewage [3] was renamed $\mathrm{wV} 8$ in our laboratory to indicate that it was obtained from the National Microbiology Laboratory (Winnipeg), and was included in the phage cocktail due to its complementary host range on common phage types (PTs) of E. coli O157:H7. Here we report on the genome and proteome of phage $\mathrm{wV} 8$, noting its very close similarity to the Salmonella phage Felix O1 [4-7]. 
Phage wV8, purified as described below, was negatively stained with $1 \%(\mathrm{w} / \mathrm{v})$ uranyl acetate for $20 \mathrm{~s}$ and the particles were observed using a LEO $12 \mathrm{AB}$ and a Philips EM 300 transmission electron microscope operating at 100 $\mathrm{kV}$ and $60 \mathrm{kV}$, respectively. Phage $\mathrm{wV} 8$ is a member of the Myoviridae and is morphologically identical to Felix O1 and related phages. Viral particles were morphologically intact and generally have extended tails (Figure 1). Measurement of 20 particles indicated phage $\mathrm{wV} 8$ has a head $70.4 \mathrm{~nm}$ in diameter and a tail $112.8 \times 16.8 \mathrm{~nm}$ long. These closely resemble those reported for phage Felix O1, in which the head measured $73 \mathrm{~nm}$ in diameter and the noncontracted tail was $113 \times 17 \mathrm{~nm}$ long [8]. Phage wV8 has a neck of $7 \times 7 \mathrm{~nm}$, a collar disk of $10 \times 2 \mathrm{~nm}$, and four fibres of $40 \times 2 \mathrm{~nm}$ that are generally folded along the tail, but may become unfolded in some particles. Tails have transverse striations of $3 \mathrm{~nm}$ periodicity, but sometimes present a pattern of overlapping subunits.

For host range studies, phage wV8 was tested for lytic activity on reference strains of 12 common E. coli O157:H7 PTs, the entire ECOR collection [9] and 12 Salmonella enterica serovars. Lytic activity on the reference $E$. coli O157:H7 PT strains and the Salmonella serovars was determined at multiplicities of infection (MOI) of between 0.001 and 10 in broth cultures in microplates incubated for $5 \mathrm{~h}$ at $37^{\circ} \mathrm{C}$ before inspection for complete lysis (no visible turbidity). Bacteria showing no visible lysis at any MOI were considered resistant to phage $\mathrm{wV8}$, while those showing complete lysis at MOIs of 10 or less were considered sensitive to phage wV8. Strains of the
ECOR collection were tested as freshly seeded bacterial lawns on agar plates spotted with $20 \mu$ l of diluted phage $\mathrm{wV} 8$ containing $10^{4}-10^{6} \mathrm{pfu}$. After incubation for $18 \mathrm{~h}$ at $37^{\circ} \mathrm{C}$, strains showing $>50 \%$ lysis were considered sensitive. Phage wV8 is highly specific for E. coli O157:H7 strains, completely lyses the 12 most common E. coli O157:H7 (PTs) isolated in Canada [10] and has no lytic activity against any of the Salmonella strains (Table 1).

Phage wV8 was propagated on E. coli strain EC990779 (ECOR strain 6, O173:H), precipitated from clarified lysates using polyethylene glycol 8000 and purified through two rounds of $\mathrm{CsCl}$ equilibrium gradient centrifugation [11]. The DNA was isolated as described by these authors and subjected to pyrosequencing at the National Microbiology Laboratory (Winnipeg, MB). Prior to annotation, the genome was opened immediately upstream of the rIIA gene so that it could be directly compared with the sequence of Felix O1. The genome was annotated using Kodon (Applied Maths, Austin, TX) and a variety of online tools http://molbiol-tools.ca including tRNAScanSE [12] and ARAGORN [13] at their default setting. The GenBank accession number for this sequence is EU877232.

The genome characteristics of wV8 (size: $88.49 \mathrm{~kb}, 38.9$ mol\%G+C, 138 ORFs, 23 tRNAs) closely resemble those of Salmonella phage Felix O1 (86.16 kb, $39.0 \mathrm{~mol} \% \mathrm{G}+\mathrm{C}$, 131 ORFs and 22 tRNAs) and, indeed many of the proteins have their closest homologs with those of Felix O1 (NC_005282). This is also substantiated by SDS-PAGE

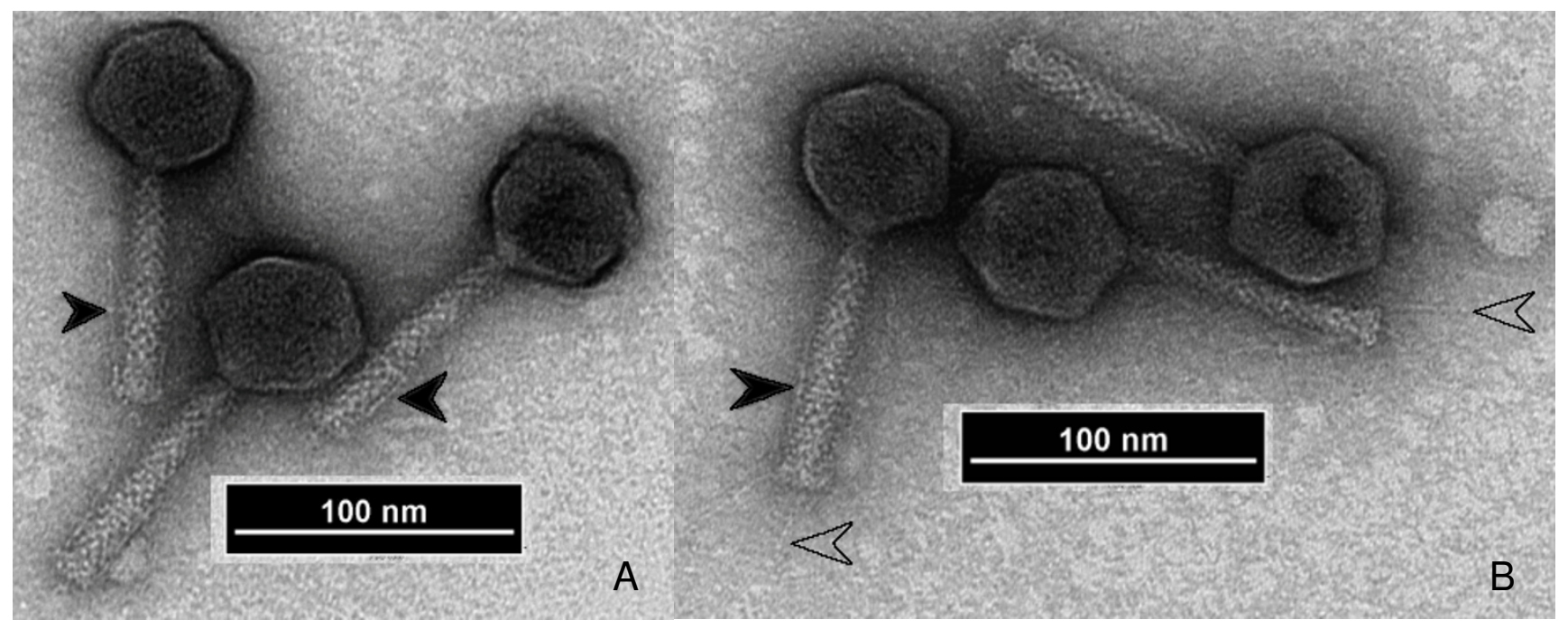

Figure I

Electron micrographs of phage wV8 showing typical myovirus morphology. Open arrowheads (Figure IB) point to extended tail fibres while filled arrowheads (Figures IA, IB) point to the more commonly observed folded tail fibres. A collar and neck can be seen on several of the particles. 
Table I: Sensitivity and resistance of bacterial cultures to bacteriophage wV8

\begin{tabular}{llll}
\hline & Bacteria & Sensitive to bacteriophage wV8 & Resistant to bacteriophage wV8 \\
\hline E. coli OI57:H7 & $\begin{array}{l}\text { Reference strains of I2 common E. coli } \\
\text { OI57:H7 phage types } \\
(\text { I strain/phage type })\end{array}$ & $\begin{array}{l}\text { All tested reference strains: phage types } \\
\text { I, 2, 4, 8, I4, 2I, 23, 24, 3I, 32, 33, 87. }\end{array}$ & None \\
Other E. coli & The ECOR collection 2 & ECOR 6 (OI73:H-); ECOR 28 & ECOR Strain No. 2, 3, 5, 7, 8, II, I4- \\
Salmonella enterica & 2 serovars: & (OI04:H2) & I9, 2I-27, 29-44, 46, 48-72 \\
& & None & S. Anatum, S. Hadar, S. Heidelberg, S. \\
Infantis, S. Kentucky, S. Meleagridis, S. \\
\end{tabular}

\footnotetext{
I The 12 most common E. coli OI57:H7 phage types that represent $>93 \%$ of E. coli OI57:H7 isolates phage typed in Canada in 1998-99 [10]. 2 The ECOR collection is a reference collection of 72 strains of $E$. coli that represents the genotypic diversity of $E$. coli, as determined by multilocus enzyme electrophoresis [9].
}

analysis of the structural proteins of $\mathrm{wV} 8$ and Felix $\mathrm{O} 1$ which show considerable similarity (Figure 2). The one notable exception lies in the largest proteins (wV8 Gp83, $91.5 \mathrm{kDa}$; and, Felix O1 orf184, $84.1 \mathrm{kDa}$ ), which bioinformatic analyses revealed to be the tail fibre proteins. Matrix-assisted laser desorption ionization quadrupole

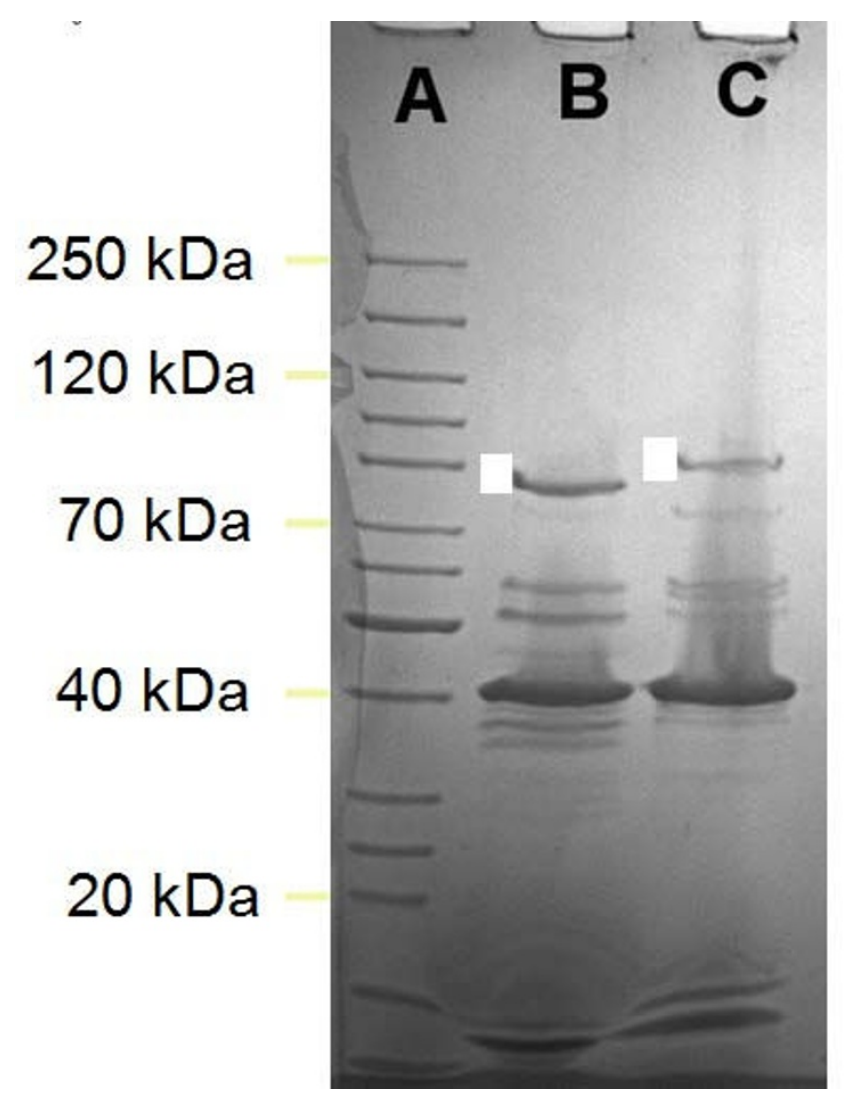

Figure 2

Structural proteins of phages Felix $\mathrm{OI}$ (lane B) and wV8 (lane C) revealed by SDS-PAGE. Clear boxes are to the left side of the phage tail fibre protein bands. time-of-flight (MALDI QqTOF) MS analysis of the wV8 protein indicates that these two proteins are homologous.

Tandem mass spectrometric (MS/MS) measurements were performed to sequence all the trypsin-digested peptides in order to obtain the high confidence protein identification in the databases. Initial MS/MS search using Mascot http:/ /www.matrixscience.com against NCBI databases retrieved a putative tail fibre protein from phage Felix O1 (NCBI: GI:38707850, NP_944923), where five sequences out of the observed 28 peptides were matched $(\mathrm{m} / \mathrm{z}$ 775.427, 1361.735, 1764.869, 2019.015, 2215.053). Using a custom wV8-specific protein database, a thorough examination of all peptide sequences confirmed the protein assignment, with these five peptides providing $44.3 \%$ sequence coverage. Sequence alignment of the Felix O1 and wV8 tail fibre orthologs using ALIGN http:// xylian.igh.cnrs.fr/bin/align-guess.cgi revealed $65.7 \%$ identity.

Tail fibre proteins from related phages typically show strong sequence similarity at the N-termini, where the protein associates with the phage tail plate. The carboxy termini, associated with receptor interaction, vary considerably. With Felix $\mathrm{O} 1$ and wV8, we see a completely different type of relationship: four regions of similarity separated by regions of dissimilarity, with both the C- and N-termini conserved (see Additional file 1) [14].

Since Felix O1 is LPS-specific [15], we analyzed wV8resistant mutants of E. coli O157:H7. An overnight broth culture of an E. coli O157:H7 strain was mixed with excess $\mathrm{wV} 8$ and incubated on plates for $24 \mathrm{~h}$. Nine independent mutants were isolated and serotyped by the E. coli (VTEC) Reference Laboratory at the Laboratory for Foodborne Zoonoses. Approximately one-half of these still serotyped as O157:H7, while half were untypable (rough) indicating that this phage may recognize, like coliphage T4, two 


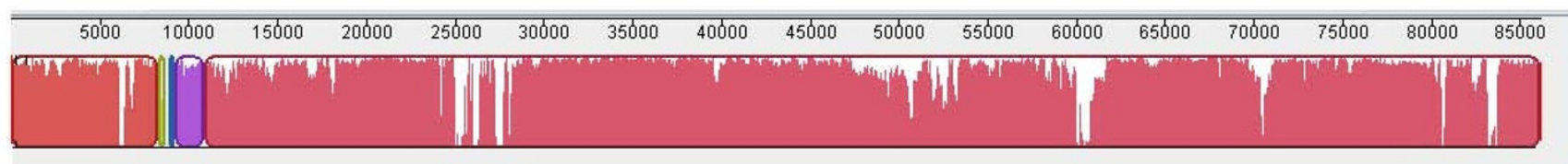

Felix 01



rIIA

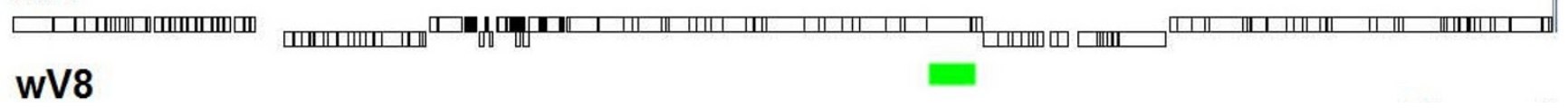

\section{Figure 3}

Alignment, based upon BLASTN of the genome of phages wV8 (top) and Felix OI (bottom). The contiguous black boxes under the phage names represent the position of the genes. Regions of nucleotide similarity are indicated by the height of the coloured bars while those regions which are dissimilar are in white. The positions of the tail fibre genes are indicated by green rectangles.

different surface receptors: lipopolysaccharide and, perhaps, an outer membrane protein.

Whole genome comparisons were made at the DNA level using Mauve [16] and Advanced Pipmaker [17] and at the protein level using CoreGenes [18]http:// binf.gmu.edu:8080/CoreGenes2.0/custdata.html. The latter program revealed that Felix O1 and wV8 share $92 \%$ of their proteins in common. Mauve analysis (Figure 3) reveals considerable sequence similarity between Felix O1 and wV8 with a few noticeable differences which centre at 11.9, 26.752 .3 , and $60 \mathrm{~kb}$ on the Felix O1 genome. The presence of heterologous sequences within these phage genomes is completely in accord with the evolution of the viruses via horizontal gene transfer [19].

Based upon an extensive analysis of relationships between prokaryotic viruses (Lavigne R, Summer EJ, Seto D, Mahadevan P, Nilsson AS, Ackermann H-W et al.: Classification of Myoviridae bacteriophages using BLASTP-tools: submitted) this level of similarity indicates that $\mathrm{wV} 8$ should be classified into the newly proposed genus, "Felix O1 viruses", along with Erwinia amylovora phage $\phi E a 21-4$.

\section{Conclusion}

E. coli O157:H7-specific phage $\mathrm{wV} 8$ is a member of the Myoviridae and is closely related to the Salmonella-specific phage, Felix O1. Their tail fibre proteins show a unique pattern of sequence relationship.

\section{Competing interests}

The authors declare that they have no competing interests.

\section{Authors' contributions}

RA originally isolated phage V8. AMK assisted in the annotation and prepared the manuscript, EJL and SO propagated and purified the phage, and together with YMS contributed to the proteome analysis. HWA and DMM carried out the electron microscopy and AV annotated the genome. AM and EJL carried out the host range studies. TW and RPJ conceived and conducted the initial host range studies, other selection procedures and the animal studies for evaluation of $\mathrm{wV} 8$ as one of a cocktail of phages for control of E. coli O157:H7 in cattle. RPJ also contributed to manuscript preparation.

\section{Additional material}

\section{Additional file 1}

ClustalW alignment of the tail fibre proteins of phages $w \mathrm{~V} 8$ and Felix O1. Alignments were carried out at EBI http://www.ebi.ac.uk/Tools/clus talw/index.html. Residues are indicated with a star $\left({ }^{*}\right)$ if identical, a colon (:) if conserved; and a period (.) if related.

Click here for file

[http://www.biomedcentral.com/content/supplementary/1743422X-6-41-S1.doc] 


\section{Acknowledgements}

We wish to thank Katherine Baldwin and Stephanie Campbell for the wV8 host range study, Nina Enriquez for the serotyping, Dr Susan J. Bach (Agriculture and Agri-Food Canada) for preliminary electron micrographs, Dr Nammalwar Sriranganathan (Virginia Polytechnic Institute and State University, Virginia-Maryland Regional College of Veterinary Medicine, USA) for providing phage Felix OI, and Dr Susan Lehman (Brock University, Canada) for unpublished data on Erwinia phage $\phi \mathrm{Ea} 2 \mathrm{I}-4$.

\section{References}

I. Waddell T, Mazzocco A, Johnson RP, Pacan J, Campbell S, Perets A, MacKinnon A, Holtslander J, Pope B, Gyles C: Control of Escherichia coli O157:H7 infection of calves by bacteriophages. 4th International International Symposium and Workshop on Shiga toxin (verocytotoxin)-producing Escherichia coli (VTEC 2000) Kyoto, Japan 2000.

2. Waddell TE, Mazzocco A, Pacan J, Johnson R, Ahmed R, Poppe C, et al.: Use of bacteriophages to control Escherichia coli 0157 infections in cattle. [U.S. patent number 6485902] 2002.

3. Ahmed R, Bopp C, Borczyk A, Kasatiya S: Phage-typing scheme for Escherichia coli O157:H7. Journal of Infectious Diseases 1987, 155:806-809.

4. Hirsh DC, Martin LD: Rapid detection of Salmonella spp. by using Felix-OI bacteriophage and high-performance liquid chromatography. Appl Environ Microbiol 1983, 45:260-264.

5. Kallings LO: Sensitivity of various salmonella strains to felix $\mathbf{0}-$ I phage. Acta Pathologica et Microbiologica Scandinavica 1967, 70:446-454.

6. Kuhn J, Suissa M, Chiswell D, Azriel A, Berman B, Shahar D, Reznick S, Sharf R, Wyse J, Bar-On T, Cohen I, Giles R, Weiser I, LubinskyMink S, Ulitzur S: A bacteriophage reagent for Salmonella: molecular studies on Felix O1. International Journal of Food Microbiology 2002, 74:217-227.

7. Felix A, Callow BR: Paratyphoid- B Vi-phage typing. Lancet 195I, 2:10-14.

8. Ackermann H-W: Salmonella phages examined in the electron microscope. Methods Mol Biol 2007, 394:21 3-234.

9. Ochman H, Selander RK: Standard reference strains of Escherichia coli from natural populations. Journal of Bacteriology 1984, 1 57:690-693.

10. Demczuk W, Ahmed R, Woodward D, Clark C, Rogers F: National Enteric Surveillance Program Annual Summary 2000 Ottawa, Canada, Health Canada; 200I:I-78.

II. Sambrook J, Russell DW: Molecular Cloning: A Laboratory Manual Third edition. Cold Spring Harbor, New York: Cold Spring Harbor Press; 2001.

12. Lowe TM, Eddy SR: tRNAscan-SE: a program for improved detection of transfer RNA genes in genomic sequence. Nucleic Acids Research 1997, 25:955-964.

13. Laslett $D$, Canback B: ARAGORN, a program to detect tRNA genes and tmRNA genes in nucleotide sequences. Nucleic Acids Research 2004, 32: II-16.

14. Kovalyova IV, Kropinski AM: The complete genomic sequence of lytic bacteriophage gh-I infecting Pseudomonas putida-evidence for close relationship to the T7 group. Virology 2003, 31 I:305-315.

15. Hudson HP, Lindberg AA, Stocker BA: Lipopolysaccharide core defects in Salmonella typhimurium mutants which are resistant to Felix $O$ phage but retain smooth character. Journal of General Microbiology 1978, 109:97-I I 2.

16. Darling AC, Mau B, Blattner FR, Perna NT: Mauve: multiple alignment of conserved genomic sequence with rearrangements. Genome Research 2004, I4:|394-|403.

17. Schwartz S, Zhang Z, Frazer KA, Smit A, Riemer C, Bouck J, Gibbs R, Hardison R, Miller W: PipMaker - a web server for aligning two genomic DNA sequences. Genome Research 2000, 10:577-586.

18. Zafar N, Mazumder R, Seto D: CoreGenes: a computational tool for identifying and cataloging "core" genes in a set of small genomes. BMC Bioinformatics 2002, 3: 12.

19. Juhala RJ, Ford ME, Duda RL, Youlton A, Hatfull GF, Hendrix RW: Genomic sequences of bacteriophages HK97 and HK022: Pervasive genetic mosaicism in the lambdoid bacteriophages. Journal of Molecular Biology 2000, 299:27-5I.
Publish with Biomed Central and every scientist can read your work free of charge

"BioMed Central will be the most significant development for disseminating the results of biomedical research in our lifetime. "

Sir Paul Nurse, Cancer Research UK

Your research papers will be:

- available free of charge to the entire biomedical community

- peer reviewed and published immediately upon acceptance

- cited in PubMed and archived on PubMed Central

- yours - you keep the copyright 